\title{
Validity of the Refraction Microtremors (ReMi) Method for Determining Shear Wave Velocities for Different Soil Types in Egypt
}

\author{
Mohamed Ahmed Gamal ${ }^{1}$, Satish Pullammanappallil ${ }^{2}$ \\ ${ }^{1}$ Geophysics Department, Cairo University, Cairo, Egypt \\ ${ }^{2}$ Optm Inc., Reno, Nevada, USA \\ E-mail:mohgamal1@yahoo.com, satish@optimsoftware.com \\ Received August 9, 2011; revised September 12, 2011; accepted October 22, 2011
}

\begin{abstract}
The Refraction Microtremor (ReMi) method is being used around the world by the geotechnical and geophysical community to determine shear-wave velocities. This is due to its faster, less expensive and accurate determination of shear wave velocities, when compared to other methods used. Unlike standard crosshole and downhole techniques, ReMi does not require any drilling. It eliminates the problem of shear-wave source and quiet site that are pre-requisites for good seismic refraction surveys. In this paper we present refraction microtremors (ReMi) measurements done at sites underlain by different soil types in Egypt. The ReMi data were collected using standard refraction equipment employing 12, 24 or 48 channels. We used deep oceanographic noise and ambient noise including energy from power generators, pile drivers and traffic. The data were processed using the SeisOpt ${ }^{\circledR} \operatorname{ReMi}^{\mathrm{TM}}$ (@ Optim, Inc.) software to reveal one-dimensional shear-wave velocity structures beneath the arrays. To access the validity of the method for the Egyptian soils, the shearwave profiles obtained from the ReMi measurements were compared to downhole and crosshole data for different soils. Comparisons demonstrate the robustness of the ReMi technique for obtaining shear-wave velocities for different soil types in Egypt.
\end{abstract}

Keywords: Refraction, Microtremors, ReMi, Crosshole, Downhole, Shear Wave, Egypt

\section{Introduction}

The refraction microtremors technique is based on two fundamental ideas. The first is that common seismicrefraction recording equipment, set out in a way almost identical to shallow P-wave refraction surveys, can effectively record surface waves. The second idea is that a simple, two-dimensional slowness-frequency (P-f) transform of a microtremors record can separate Rayleigh waves from other seismic arrivals, and allow recognition of true phase velocity against apparent velocities. Two essential factors that allow exploration equipment to record surfacewave velocity dispersion, with a minimum of field effort, are the use of a single geophone sensor at each channel, rather than a geophone "group array", and the use of a linear spread of 12 or more geophone sensor channels. Single geophones are the most commonly available type, and are typically used for refraction rather than reflection surveying. The advantages of ReMi from a seismic surveying point of view are several, including the following: It requires only standard refraction equipment already owned by most consultants and Universities; it requires no triggered source of wave energy; and it will work best in a seismically noisy urban setting. Traffic and other vehicles, and possibly the wind responses of trees, buildings, and utility standards provide the surface waves this method analyses [1,2].

In this paper we present case studies that show applications of the ReMi method for mapping velocities in different geologic provinces in Egypt. Even though Egypt is a small country, there are large variations in soil properties. This could be the result of inerplate tectonics (two big seas Red and Mediterranean), the existence of Nile valley deposits, and the presence of stable African shield deserts and Lagoons and artificial lakes [3]. 


\section{Brief Geologic Setting of the Study Area}

The study area is located in the northern part of Egypt. The ReMi studies were conducted at eight sites located between longitudes $29^{\circ} 30^{\prime}$ and $33^{\circ} \mathrm{E}$ and latitudes $29^{\circ}$ and $32^{\circ} \mathrm{N}$. The area is bound to the East by Gulf of Suez, from north by the Mediterranean Sea Figure 1.

The River Nile plays a major role in the formation and evolution of the alluvial deposits surrounding the Nile Valley. The soil structure has evolved based on the interaction between the Nile basin, Mediterranean Sea and Gulf of Suez. Ground water exists at all sites except Mokattam, which is located in a relatively high area.

Following is a brief description of the geologic setting of the eight sites [3].

\subsection{Damietta}

This area lies within the Mediterranean foreshore province, an area of low relief terrain extending along the entire northern coast Figure 1. The landforms are predominantly sand sheets and coastal depressions. Different beach morphology is evident in the area. Changes in the sorting processes have resulted in the following units:

1) River sand.

The Nile River sands are moderately sorted ranging in size from fine-to medium-grained sands. This fluvial facies is characterized by the presence of high percentages of ooids, pyrite, sponge spicules and gypsum.

2) Coastal dune sand.

These are very well-sorted and are very rich in fine-to medium grained laminated sands. They are characterized by the lowest proportions of carbonate fragments and also by the abundance of heavy minerals.

3) Accretion ridge sand.

This facies is very poorly sorted, varying in size from very fine to coarse sands.

4) Beach sand.

The beach sands are well-sorted, fine to mediumgrained sands. This facies is characterized by presence of heavy minerals as well as by the presence of some reworked marine biogenic components.

5) Near shore sand.

This facies is composed of poorly to moderately sorted muddy sands. Carbonate fragments, ooids and gypsum are relatively significant components.

6) Mud Facies.

This facies is composed of mixtures of silt and clay, and have a low sand content.

7) Lagoon mud.

The lagoonal deposits have the highest proportions of carbonate grains and nodules, plant remains, and shell fragments.

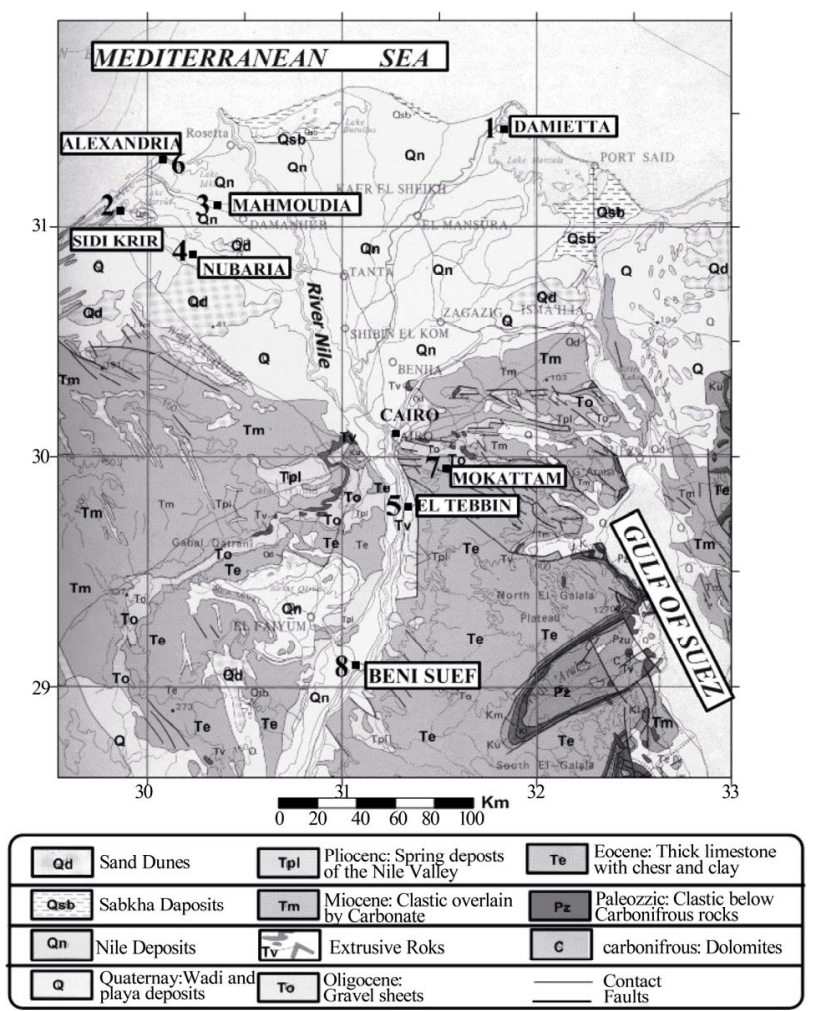

Figure 1. Geologic map for northern Egypt showing the 8 ReMi test locations, 1-Damietta, 2-Sidi Krir, 3-Mahmoudia, 4-Nubaria, 5-EL Tebbin, 6-Alexandria, 7-Mokattam and 8Beni Suef [4].

\subsection{Sidi Krir and Alexandria}

Both these sites are located in the Mediterranean coastal plain province. The Mediterranean coastal plain is characterized by the presence of a number of elongated ridges which run parallel to the coast, separated by longitudinal depressions [3]. These ridges are composed mainly of oolitic limestone. They seem to represent successive fossil off-shore bars that were formed by the receding Mediterranean during the Pleistocene. The depressions which separate the bars contain lagoonal deposits (evaporites and marls).

\subsection{Mahmoudia and Nubaria}

Both of these sites lie within the Nile Valley and Nile Delta deposits, where Wadi and playa deposits of quarternary age are abundant Figure 1.

\subsection{EL Tebbin}

This site is characterized by Wadi deposits. They lie unconformably over the underlying Eocene limestone and are made up of alternating poorly-bedded gravel beds (sometimes reach thickness exceeding $20 \mathrm{~m}$ ) and thin 
coarse sand-pebble beds. The gravels are mostly dark brown limestone and chert. They range in size from pebbles to cobbles which are poorly sorted. The gravels are embedded in sandy matrix.

\subsection{Mokattam}

The Mokattam area deposits can be classified into Middle Eocene and Upper Eocene. The middle Eocene is formed of carbonate rocks (limestone and marl) and the Upper Eocene is formed of classic sediments (shale and sands).

\subsection{Beni Suef}

This is site is made up Nile River deposits. They are composed of cobbles and gravel sized sediments, alternating with coarse to fine grained sands and gravels. Inter bedded within it are a series of red brown clays and thin fine grained sand and silt laminate which in some parts crop out along Nile banks and the valley. These sediments seem to be derived from deeply leached terrain and from local sources.

\section{ReMi Data Processing}

ReMi processing involves three steps: Velocity Spectral Analysis, Rayleigh Phase-Velocity Dispersion Picking, and Shear-Wave Velocity Modeling:

\subsection{Velocity Spectral Analysis}

The basis of the velocity spectral analysis is the p-tau transformation, or "slantstack," described by Thorson and Claerbout (1985) [5]. This transformation takes a record section of multiple seismograms, with seismogram amplitudes relative to distance and time (x-t), and converts it to amplitudes relative to the ray parameter (the inverse of apparent velocity) and an intercept time tau. It is familiar to array analysts as "beam forming" and has similar objectives to a two-dimensional Fourierspectrum or " $F-K$ "' analysis as described by Horike (1985) [6]. Clayton and McMechan (1981) [7] and Fuis et al. (1984) [8] used the p-tau transformation as an initial step in P-wave refraction velocity analysis.

McMechan and Yedlin (1981) [9] developed the P-f technique (The "p" stands for slowness or inverse of velocity and "f" stands for frequency. Plotting dispersion curve in the "P-f" domain allows the Rayleigh wave phases to be separated from other arrivals) and tested it against synthetic surface waves, and reverberations seen on controlled-source multichannel seismic records. Park et al. (1998) [10] applied the P-f technique to active- source MASW records. All phases in the record are present in the resulting (P-f) image that shows the power at each combination of phase slowness and frequency. Dispersive phases show the distinct curve of normal modes in low-velocity surface layers: sloping down from high phase velocities (low slowness) at low frequencies, to lower phase velocities (high slowness) at higher frequencies. Miller et al. (2000) [11] examine P-f-domain power spectra of MASW records along a profile to define lateral variations in dispersion curves and thus in shear velocities.

The distinctive slope of dispersive waves is a real advantage of the P-f analysis. Other arrivals that appear in microtremors records, such as body waves and air waves, cannot have such a slope. The P-f spectral power image will show where such waves have significant energy. Even if most of the energy in a seismic record is a phase other than Rayleigh waves, the P-f analysis will separate that energy in the slowness-frequency plot away from the dispersion curves this technique interprets. By recording many channels, retaining complete vertical seismograms, and employing the P-f transform, this method can successfully analyze Rayleigh dispersion where SASW techniques cannot.

\subsection{Rayleigh Phase-Velocity Dispersion Picking}

This analysis adds only a spectral power-ratio calculation to McMechan and Yedlin's (1981) [9] technique [9], for spectral normalization of the noise records. The ability to pick and interpret dispersion curves directly from the P-f images of spectral ratio parallels the coherence checks in the SASW technique [12] and the power criterion in the MASW technique [13]. Picking phase velocities at the frequencies where a slope or a peak in spectral ratio occurs clearly locates the dispersion curve. Picks are not made at frequencies without a definite peak in spectral ratio, often below $4 \mathrm{~Hz}$ and above $14 \mathrm{~Hz}$ where an identifiable dispersive surface wave does not appear. Often, the P-f image directly shows the average velocity to 30 meters depth, from the phase velocity of a strong peak ratio appearing at $4 \mathrm{~Hz}$, for soft sites, or nearer to $8 \mathrm{~Hz}$, at harder sites.

Picking is done along a "lowest-velocity envelope" bounding the energy appearing in the P-f image. It is possible to pick this lowest-velocity envelope in a way that puts confidence limits on the phase velocities, as well as on the inverted velocity profile. Picking a surface-wave dispersion curve along an envelope of the lowest phase velocities having high spectral ratio at each frequency has a further desirable effect. Since highermode Rayleigh waves have phase velocities above those of the fundamental mode, the refraction microtremors 
technique preferentially yields the fundamental-mode velocities. Higher modes may appear as separate dispersion trends on the P-f images, if they are nearly as energetic as the fundamental.

Spatial aliasing will contribute to artifacts in the slowness-frequency spectral-ratio images. The artifacts slope on the P-f images in a direction opposite to normal-mode dispersion. The p-tau transform is done in the space and time domain, however, so even the aliased frequencies preserve some information. The seismic waves are not continuously harmonic, but arrive in groups. Further, the refraction microtremors analysis has not just two seismograms, but 12 or more. So, severe slowness wraparound does not occur until well above the spatial Nyquist frequency.

\subsection{Shear Wave Velocity Modeling}

The refraction microtremors method interactively forward-models the normal-mode dispersion data picked from the P-f images with a code adapted from Saito (1979, 1988) [14], [15] in 1992 by Zneg and Anderson (1995) [16]. This code produces results identical to those of the forward-modeling codes used by Iwata et al. (1998) [17], and by Xia et al. (1999) [18] within their inversion procedure. The modeling iterates on phase velocity at each period (or frequency), reports when a solution has not been found within the iteration parameters, and can model velocity reversals with depth.

\section{Data Acquisition}

\subsection{ReMi Data}

Figure1 shows the map with all tested sites, where ReMi data were taken. All ReMi data were collected by putting the center of the ReMi profile over the center of the receiving borehole. Almost all the sites were noisy, with noise coming from power generators, heavy machines for construction work, wind and traffic. The ReMi analysis presented here was developed from a 12 to 48 receivers (14 Hz. geophones) set along a straight-line array with different receiver spacing as will be discussed later. Unfiltered 20 second records were collected at each site. Aside from initial reconnaissance, the fieldwork to conduct the ReMi survey, including setup, acquisition and breakdown took less than an hour with a two person crew for each profile Figure 2.

\subsection{Crosshole and Downhole Data}

For crosshole seismic survey, we followed the method specified by ASTM D 4428. A seismic source Figure 3 is placed, at different depths (1 - $40 \mathrm{~m})$, in one borehole (source) facing the recording orthogonal geophones (receivers) at the same depths in the other boreholes. Two triaxial-seismic geophones are placed at same depths as the source in the recording boreholes. The raw data obtained from a crosshole survey are the travel times for compressional and shear waves from the source to the geophones. The distance between the source and the two recording boreholes are 3 and $6 \mathrm{~m}$ respectively (ASTM $\mathrm{D}$ 4428). Downhole data acquisition is different from crosshole in that only one recording borehole is used and the source of shear waves is placed about $1 \mathrm{~m}$ from the well on the surface (ASTM D7400). The source of shear wave is a wooden plate that is stroked in opposite directions to obtain shear wave reversals with opposite directions +ve and -ve.

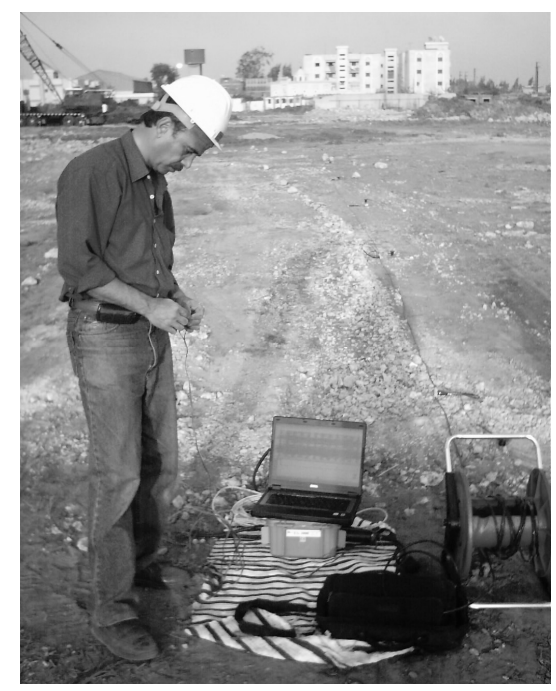

Figure 2. A pictures showing data acquisition for ReMi test using ES-3000 12 channels Geometrics seismograph.

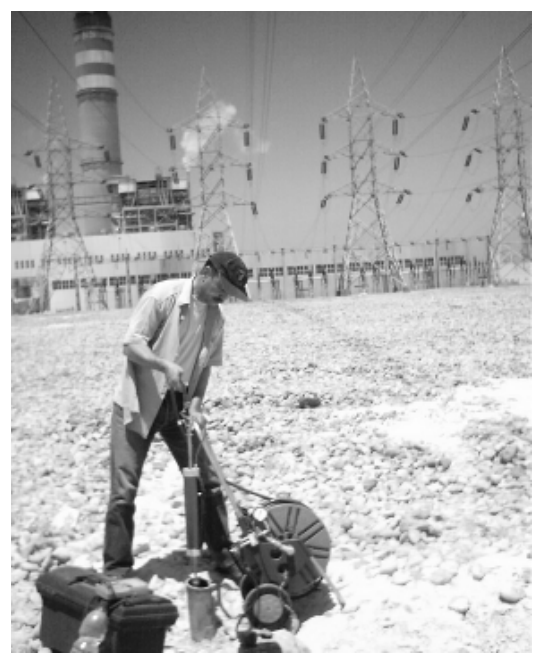

Figure 3. Ballard borehole seismic source S-wave enhanced. 


\section{Data Analysis and Interpretation}

We used Reflex 2010 and SeisImager software to analyze the crosshole and downhole data. Different filters and processing steps were applied to the data for better viewing of arrival times. The reverse S-wave arrivals were overlapped for accurately S-wave arrival time's determination Figure 4.

The following is a brief description to the estimated Swave velocities obtained from ReMi, crosshole or downhole seismic tests for each site.

\subsection{Damietta}

ReMi data at this site was acquired using a 12 channel seismograph. Fifty "noise records" were obtained every 8 seconds for a total of $400 \mathrm{sec}$ microtremors data. Figures 5 and 6 show the velocity spectrum (P-f image) and corresponding dispersion curve and picks obtained for Damietta site. The Picks were then modeled to produce the shear-wave velocity model as shown in Figure 7. The site is full of noise generated from loading and unloading of containers from ships inside the harbor and also from heavy traffic. The soil of Damietta (one of the weakest soils in Egypt) show average shear wave velocity between 120 - 200 m/s Figure 7. Both crosshole and ReMi models show a low-velocity zone exist at depths between 13 - $28 \mathrm{~m}$. This layer is confirmed from drilling data (very soft clay).

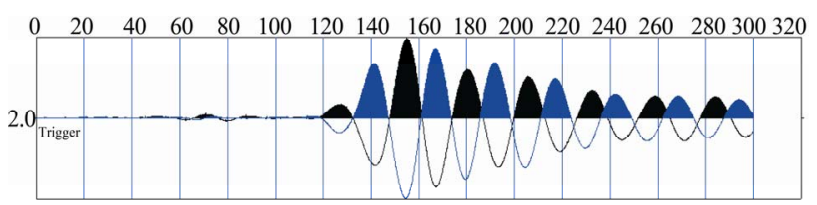

Figure 4. Example of recorded S-wave seismograms showing S-wave arrival time at 120 msec for a downhole test (Damietta site). both +ve (black) and -ve (Blue) s-arrivals are shown (Reversals).

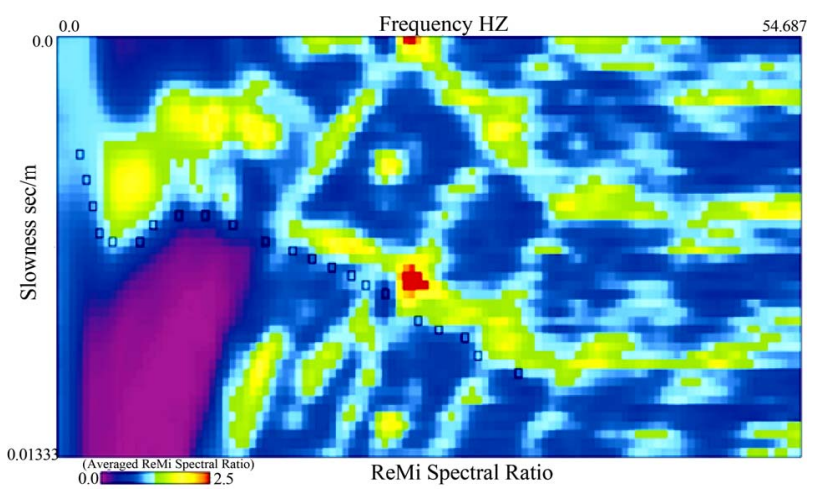

Figure 5. Velocity spectrum (P-f Image) with dispersion Modeling picks derived for Damietta site.

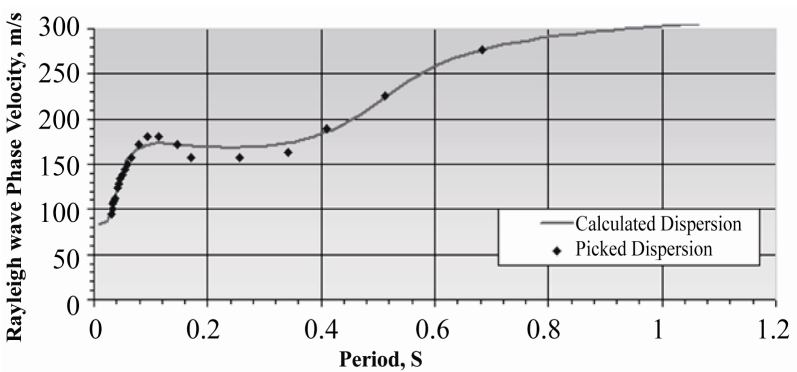

Figure 6. Dispersion curve and corresponding picks Obtained for Damietta site.

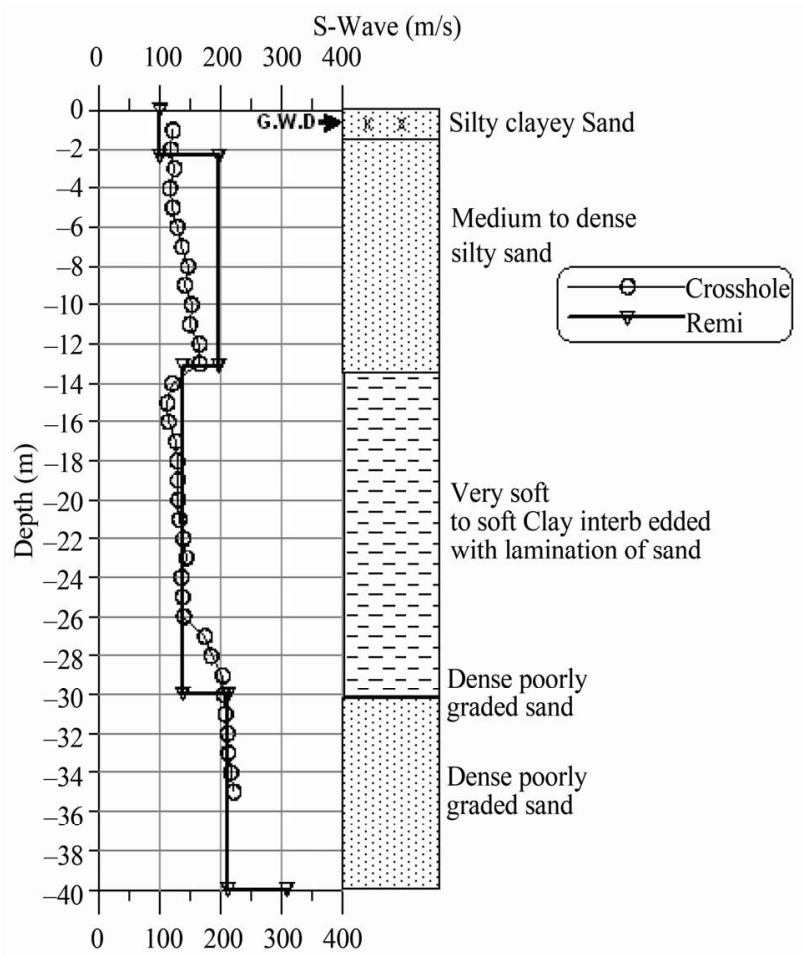

Figure 7. Comparison between shear wave velocities $\mathrm{Ob}$ tained from ReMi and crosshole tests for Damietta site.

\subsection{Sidi Krir}

ReMi data was acquired using a 12 channel seismograph. Fifty "8 seconds" noise records were collected and processed as mentioned earlier Figures 8 and 9. Most the noise at this site was generated from power generators inside an operating electrical power station. The average shear wave velocity in the site is between $400-600 \mathrm{~m} / \mathrm{s}$ Figure 10. ReMi and crosshole tests are in good agreement except at depth 3 - $8 \mathrm{~m}$ where the ReMi model shows a high-velocity zone of $1600 \mathrm{~m} / \mathrm{s}$. However, the site has several buried utilities and cultural artifacts in the limestone layer (personal communication with power station staff), which may be affecting the data acquired for ReMi test. 


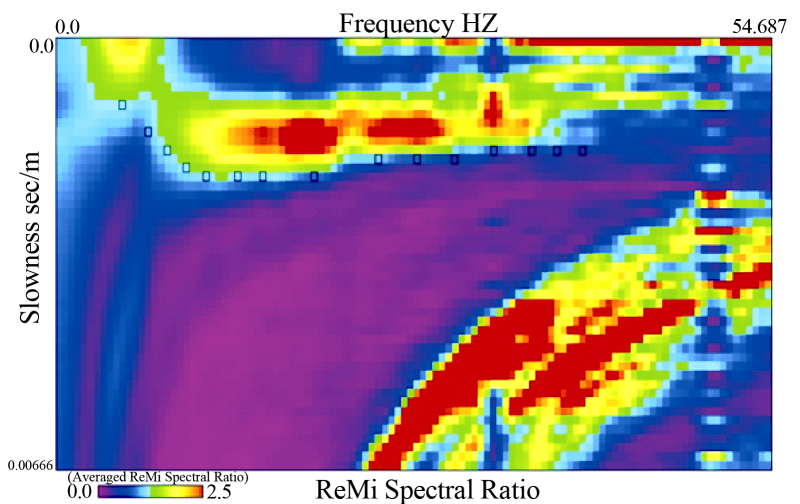

Figure 8. Velocity spectrum (P-f Image) with dispersion Modeling picks derived for Sidi Krir site.

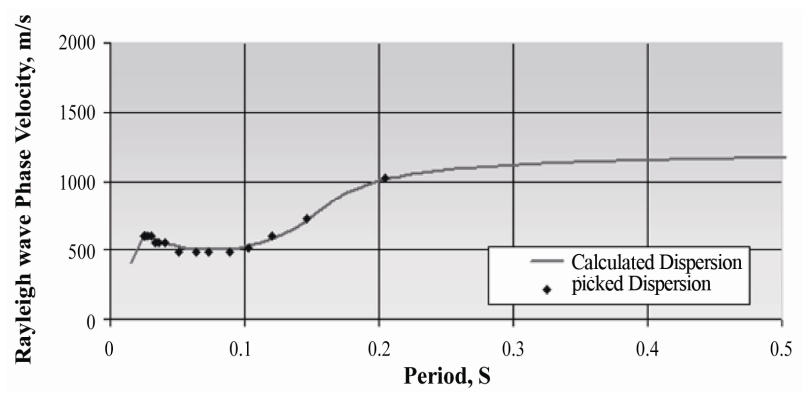

Figure 9. Dispersion curve and corresponding picks Obtained for Sidi Krir site.

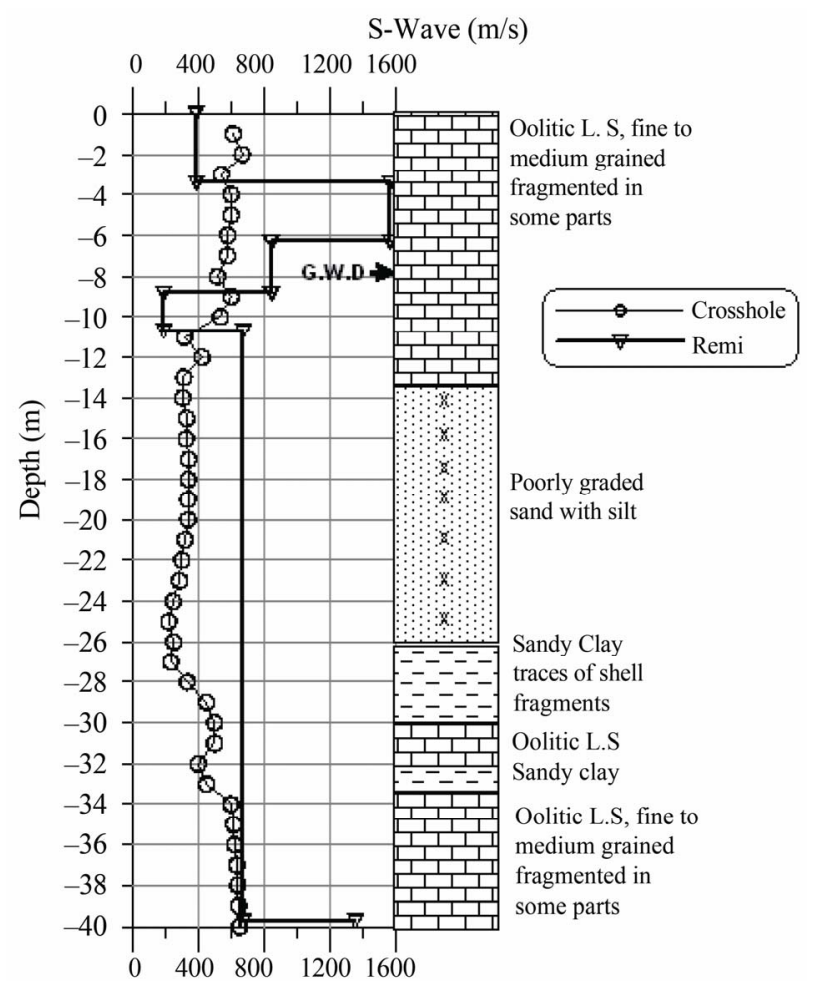

Figure 10. Comparison between shear wave velocities Obtained from ReMi And crosshole tests for Sidi Krir site.

\subsection{Mahmoudia}

ReMi data was acquired using a 12-channel system and noise was dominated by loaders and hammers that were demolishing old house at this site. This made acquiring crosshole data a challenge at this site when compared with ReMi data. Fifty records of noise "8 seconds each" were collected. P-f image, Picks and corresponding dispersion curves are shown in Figures 11 and 12. The obtained S-wave is between $100-350 \mathrm{~m} / \mathrm{s}$, ReMi data is once again in good agreement with the crosshole data Figure 13. The only big difference between ReMi and crosshole data occur at depths between 30 - $40 \mathrm{~m}$ at which crosshole source is not powerful enough to overcome the noise in this site.

\subsection{Nubaria}

The soils underlying the Nubaria are very similar to that of Mahmoudia (except the fill layer found at Mahmoudia). Both are considered the extension to Nile delta deposits. ReMi data acquisition was made using a 48 channel seismograph. Twenty records of "20 seconds" each were collected resulting in a higher resolution P-f images and dispersion curve Figures 14 and 15 compared to the dispersion curves from 12 channel "8 second" records. Figure 16 shows comparison of S-wave

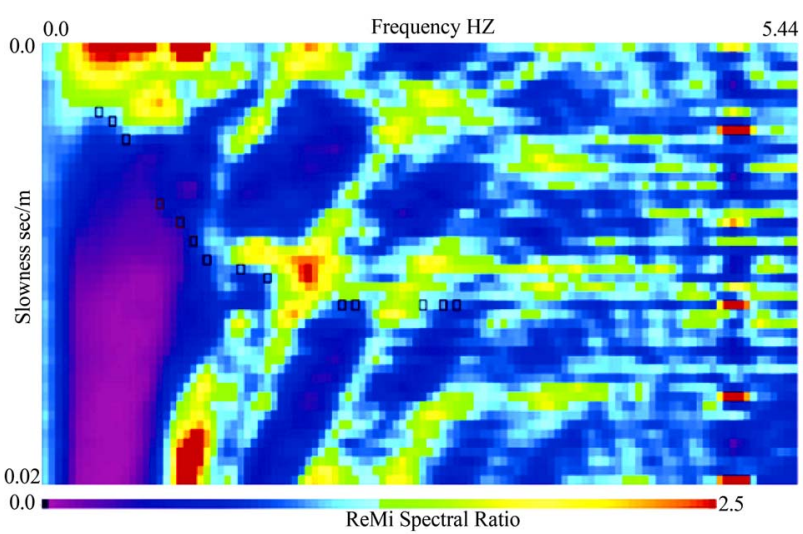

Figure 11. Velocity spectrum (P-f Image) with dispersion Modeling picks derived for Mahmoudia site.

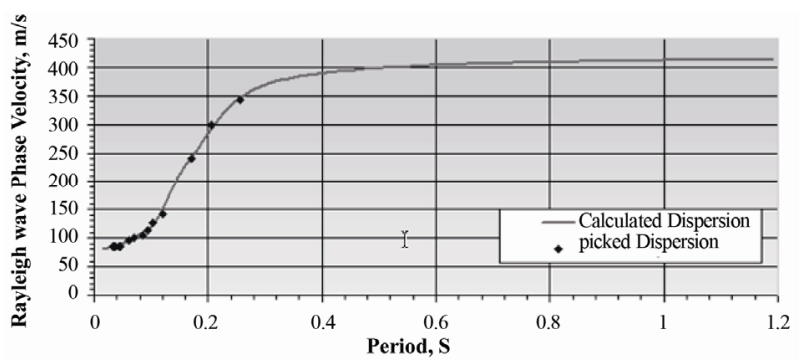

Figure 12. Dispersion curve and corresponding picks Obtained for Mahmoudia site. 


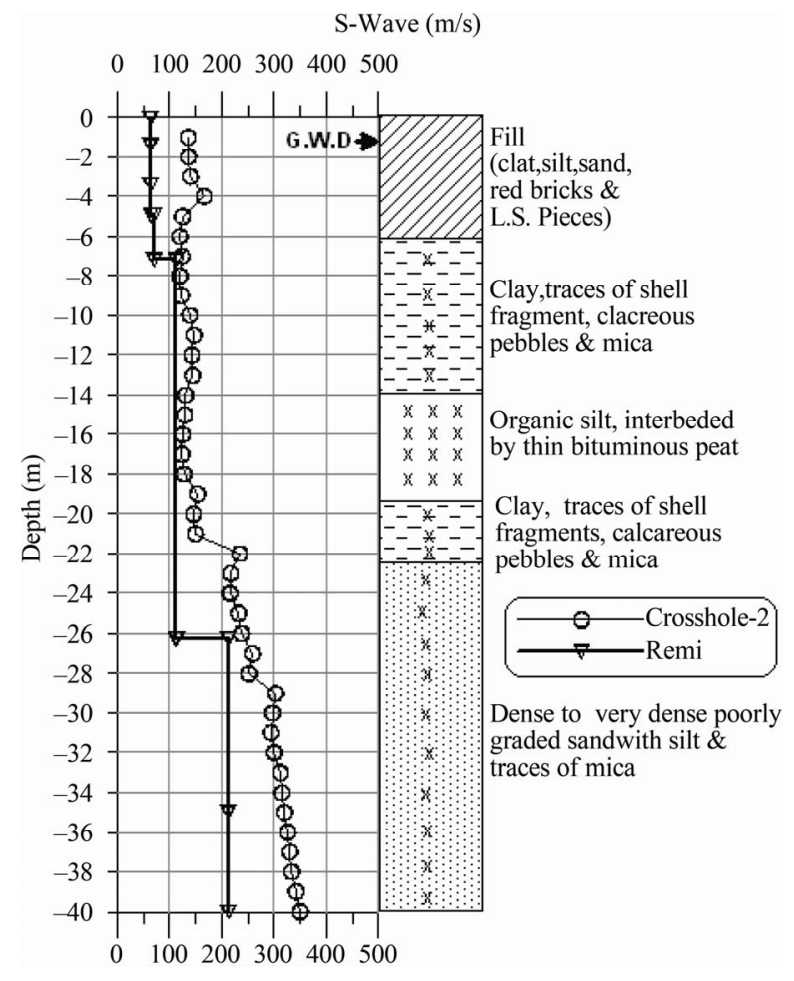

Figure 13. Comparison between shear wave velocities obtained from ReMi and crosshole tests for Mahmoudia site.

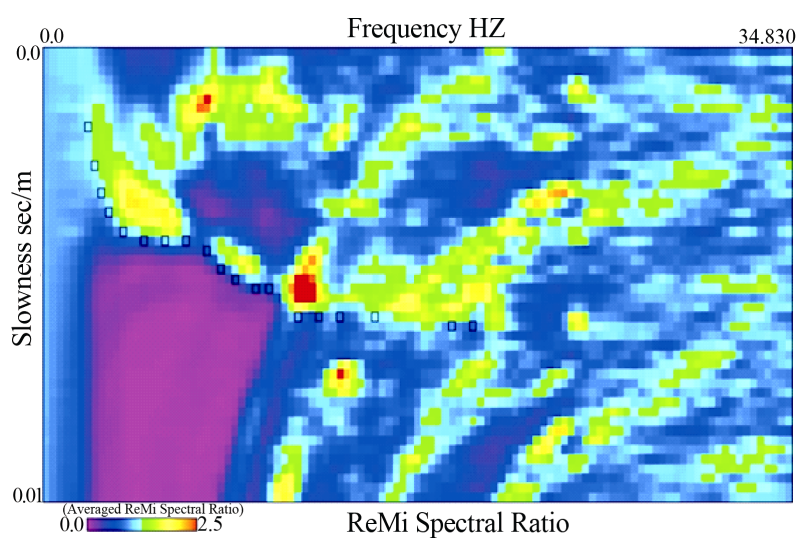

Figure 14. Velocity spectrum (P-f Image) with dispersion Modeling picks derived for Nubaria site.

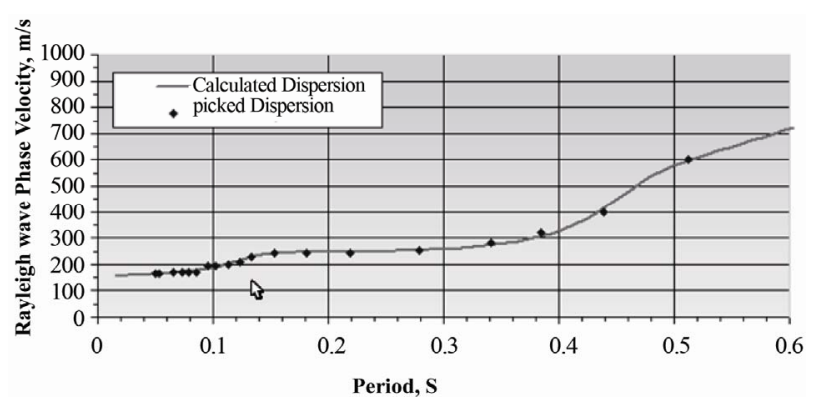

Figure 15. Dispersion curve and corresponding picks obtained for Nubaria site.

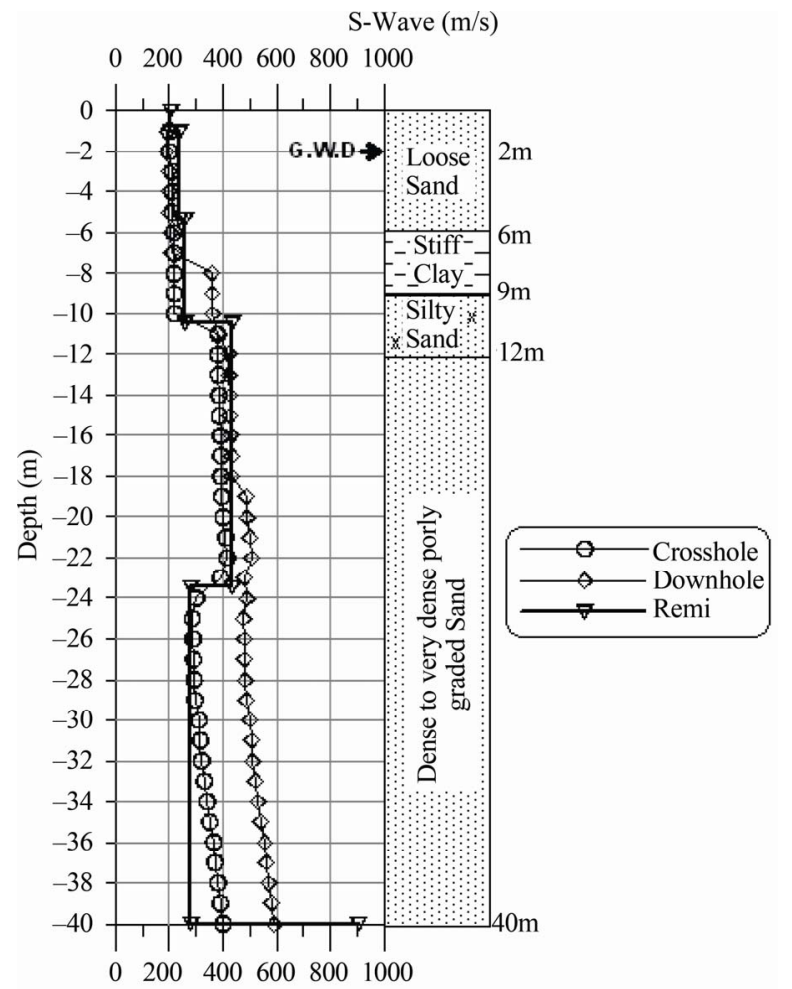

Figure 16. Comparison between shear wave velocities obtained from ReMi and crosshole tests for Nubaria site.

velocity obtained from ReMi models and crosshole or downhole data. Using 48 channel 20 seconds make the ReMi data in a better agreement to the crosshole data. The obtained shear wave velocity is between $200-600$ $\mathrm{m} / \mathrm{s}$. ReMi data succeeded at this site to show a shear wave velocity reversal for a depth between $24-40 \mathrm{~m}$.

\subsection{EL Tebbin}

The soils underlying the EL Tebbin site are very complex due to the alternating layers of gravel sheets within the soil column. Twenty files "20 seconds" each of ReMi data were acquired using a 48 channel seismograph. Data collection was done at night, so the main noise used was the deep oceanographic noise and little nearby traffic. This was more than sufficient to generate a good dispersion curve Figures 17and 18. Figure 19 shows comparison between the models obtained from both ReMi, and downhole data. The S-wave velocity is ranging between $300-1000 \mathrm{~m} / \mathrm{s}$.

\subsection{Alexandria}

Traffic and construction site activity provided ample noise at this site. Twenty records "20 seconds" each were collected using a 48 channel seismograph. P-f images 
and dispersion curves are shown in Figures 20 and 21. The shear wave profile Figure 22 is ranging between $200-1400 \mathrm{~m} / \mathrm{s}$. No crosshole or downhole data were collected for this site, however the S-wave velocity model succeeds to monitor the bedrock depth at $13 \mathrm{~m}$.

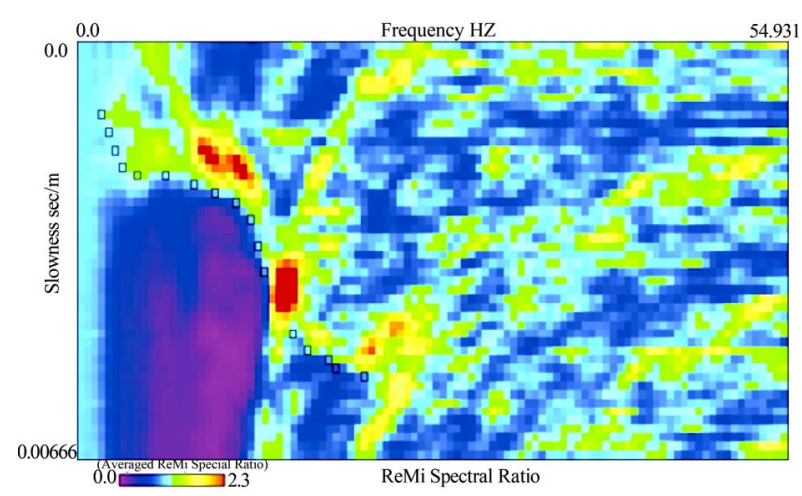

Figure 17. Velocity spectrum (P-f Image) with dispersion Modeling picks derived for EL Tebbin site.

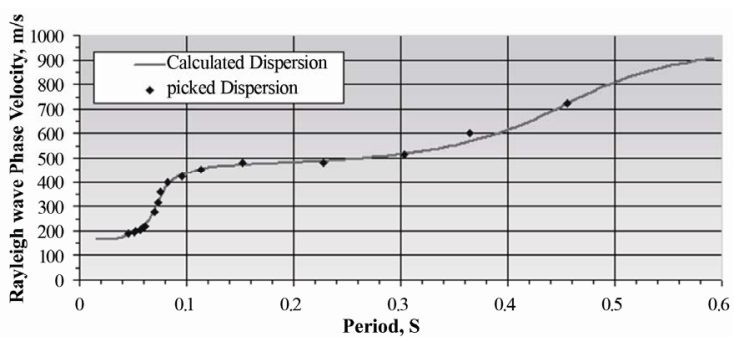

Figure 18. Dispersion curve and corresponding picks obtained for EL Tebbin site.

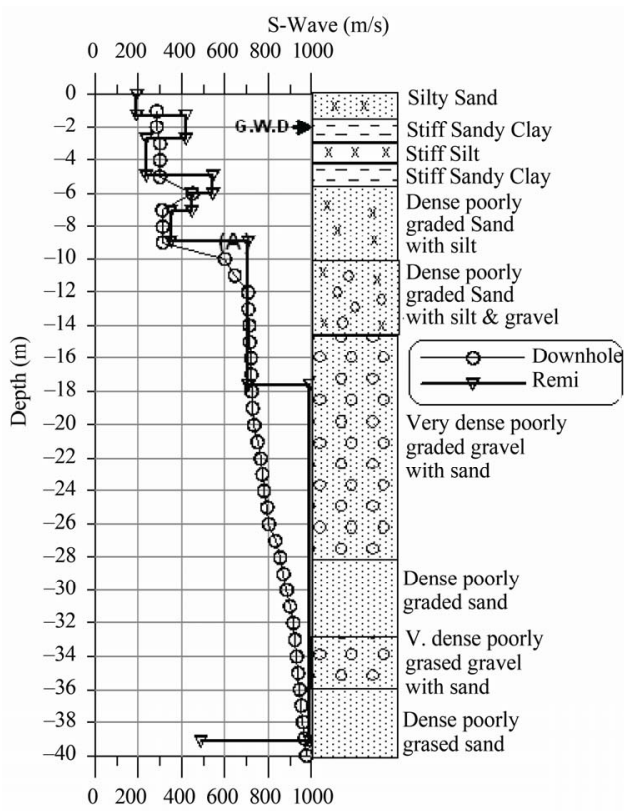

Figure 19. Comparison between shear wave velocities obtained from ReMi and crosshole tests for EL Tebbin site.

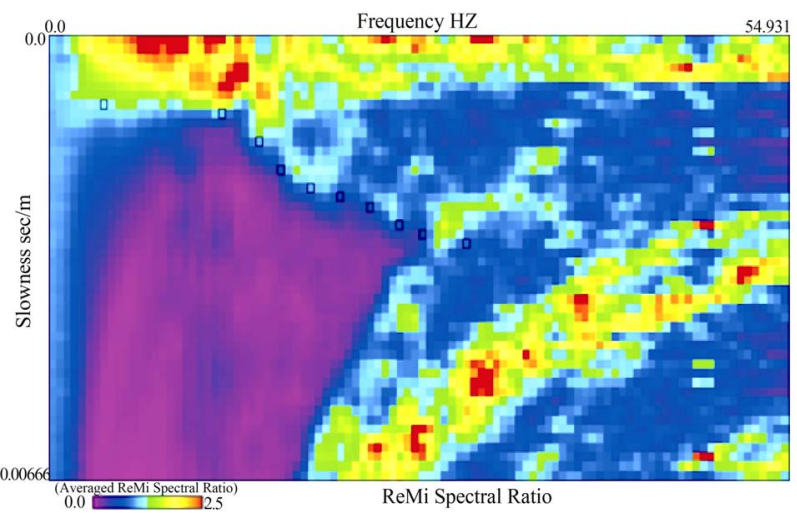

Figure 20. Velocity spectrum (P-f Image) with dispersion Modeling picks derived for Alexanderia site.

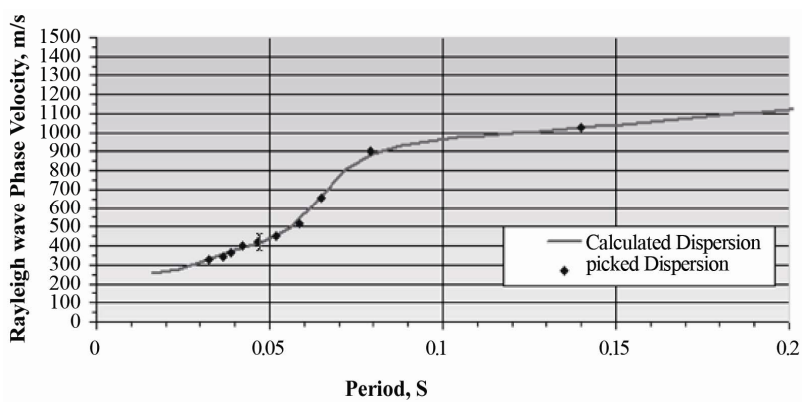

Figure 21. Dispersion curve and corresponding picks obtained for Alexanderia site.

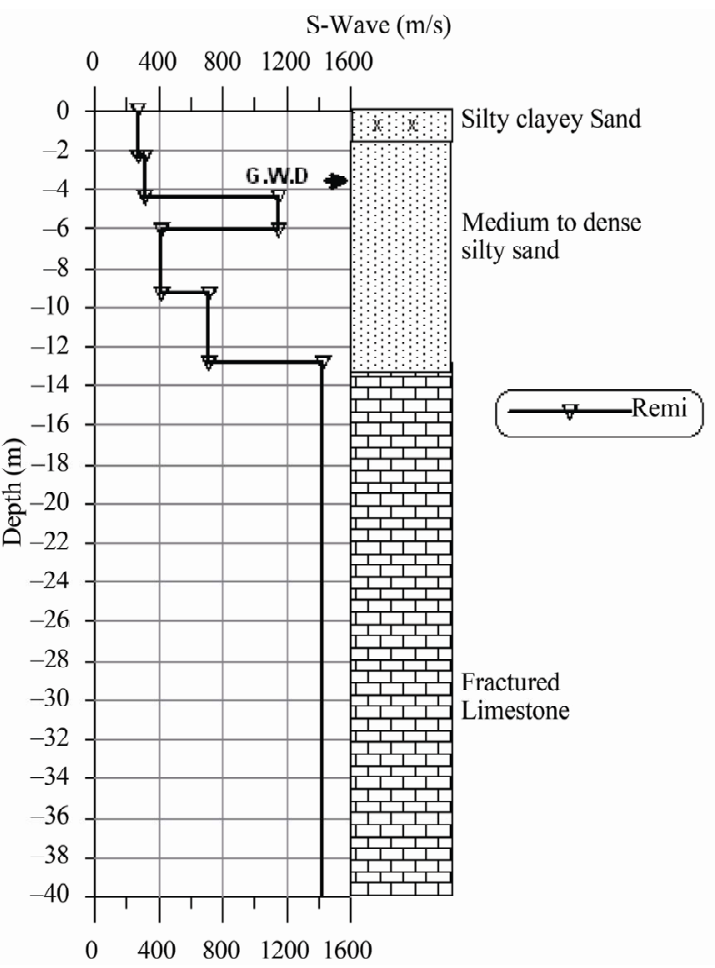

Figure 22. Shear wave velocity obtained from ReMi test for Alexanderia site. 


\subsection{Mokattam}

This site is underlain by limestone except for the upper $16 \mathrm{~m}$ which is composed of sand and sandstone. Twenty files "20 seconds" each were collected for ReMi data using a 48 channel seismograph. Deep noise and nearby traffic provided ample noise at this site. The P-f image and dispersion curves are shown in Figures 23 and 24. The ReMi models Figure 25 show higher velocities at $17 \mathrm{~m}$ that seem to correspond to the limestone bedrock.

\subsection{Beni Suef}

At this site the soil is rocky except in the upper $6 \mathrm{~m}$ which is sandy gravel. No ReMi data were collected, however shallow reflection survey data were acquired. The reflection records were only 0.5 seconds long, resulting in a low-resolution dispersion curve Figures 26 and $\mathbf{2 7}$ due to the shortness of the records. However the curve was distinct and the picks made resulted in a model that is in good agreement with the available crosshole data. The average shear wave obtained is between $600-1200 \mathrm{~m} / \mathrm{s}$. The bedrock depth detected from ReMi model is at about 9m depth Figure 28.

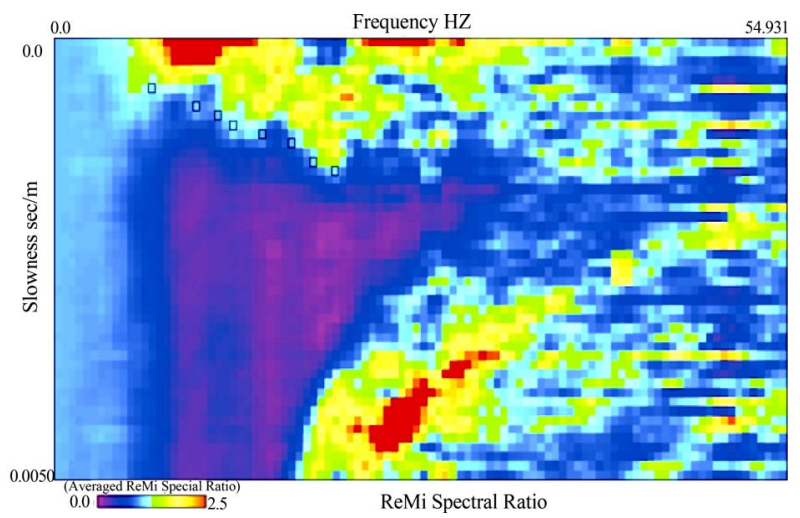

Figure 23. Velocity spectrum (P-f Image) with dispersion Modeling picks derived for Mokattam site.

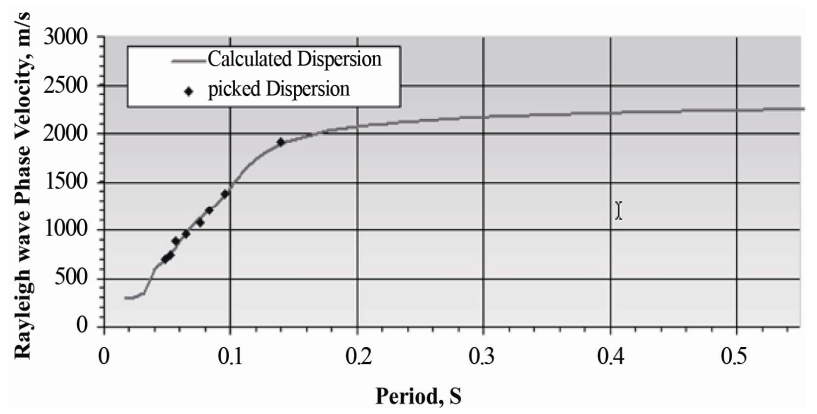

Figure 24. Dispersion curve and corresponding picks obtained for Mokattam site.

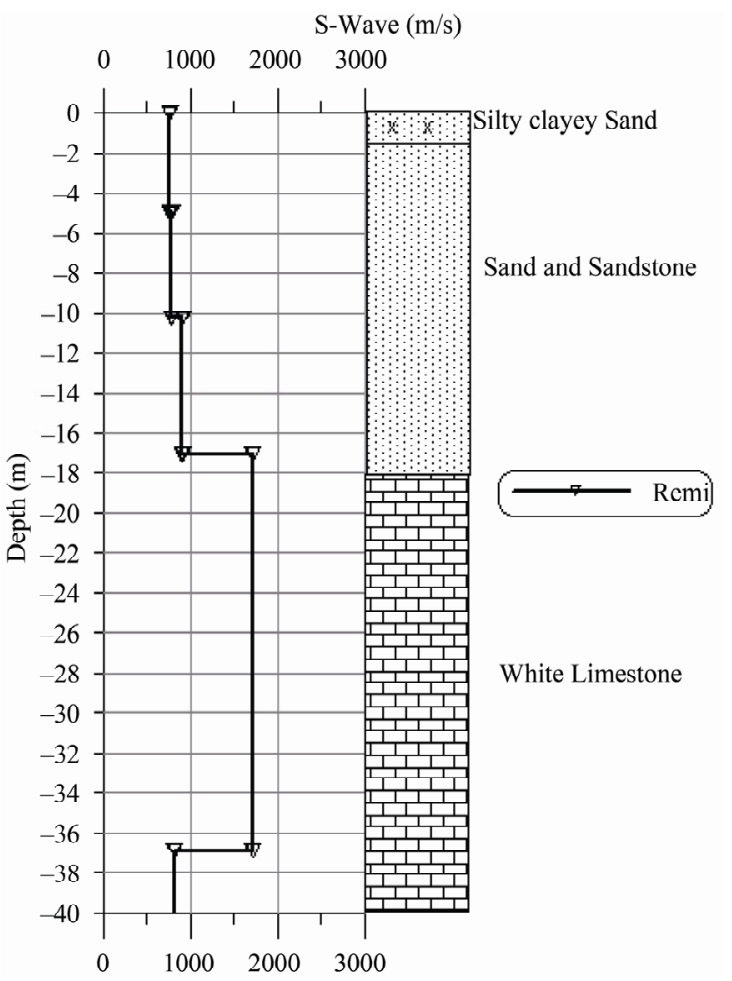

Figure 25. Shear wave velocity obtained from ReMi test for Mokattam site.

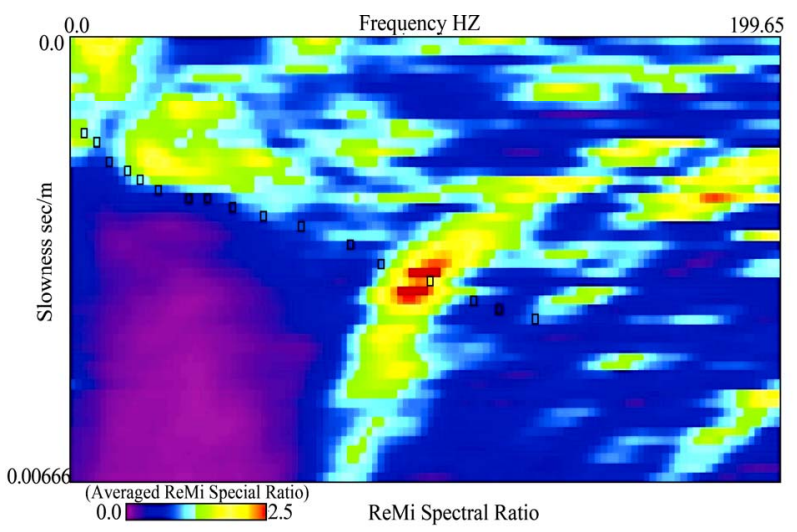

Figure 26. Velocity spectrum (P-f Image) with dispersion Modeling picks derived for Beni Suef site.

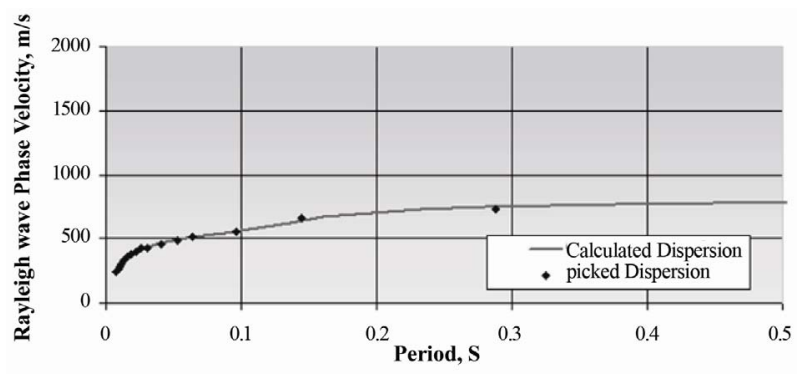

Figure 27. Dispersion curve and corresponding picks obtained for Beni Suef site. 


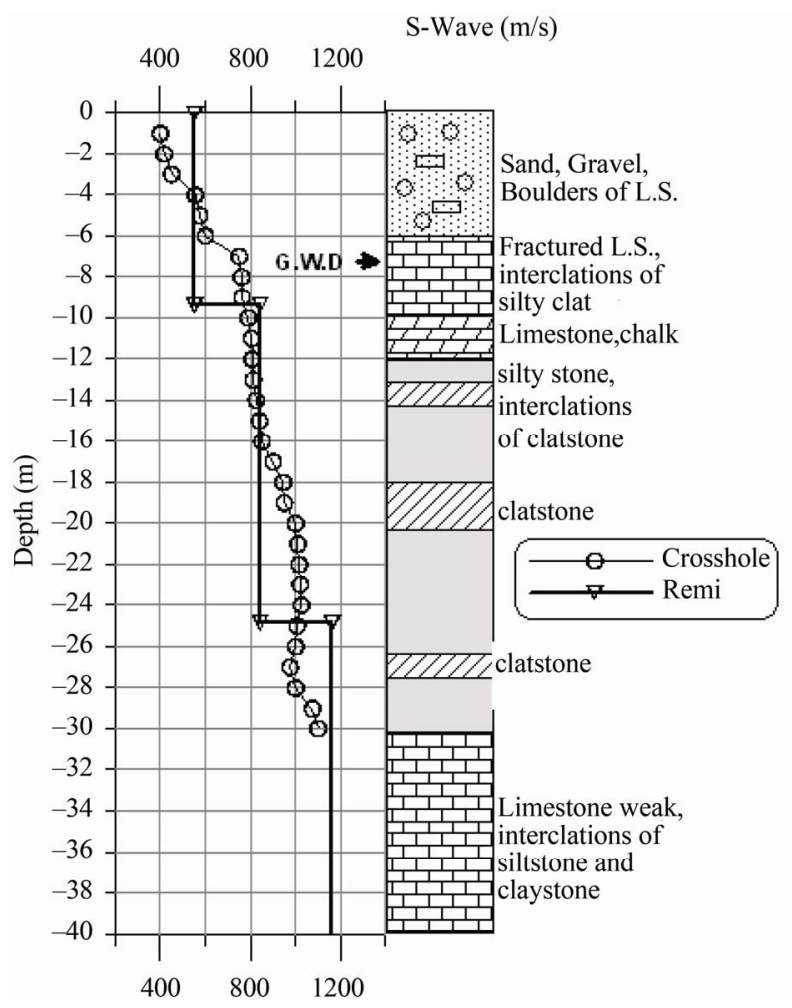

Figure 28. Shear wave velocity obtained from ReMi Data, using 0.5 seconds reflection records for Beni Suef site.

\section{Conclusions}

The limitations of ReMi are a result of the acquisition parameters and frequency content of the noise being recorded. Maximum depth of resolution is the length of the profile, with resolution decreasing with depth. The thinnest layer one can resolve is a function of geophone spacing and maximum frequency of the recorded data. Smaller geophone spacing and higher frequencies help resolve thinner layers in the subsurface. Lower frequentcies provide resolution at depth. Ambient noise by itself may lack high frequencies and so an active source (e.g. hammer hits) can be used the augment the high frequency content of the recorded data. We modeled the dispersion picks by interactive forward modeling. We started by using any number of layers and fit the dispersion picks by adding more layers, changing the velocity of each layer and varying the depth of the layers. Modeling was achieved by first starting with three layers and fitting the high frequency dispersion picks that control the shallow velocities. More layers were only added if required by the data. Both velocities and depth of shallow layers are determined before the low frequency picks are modeled to get velocities of the deeper layers.

The data were modeled blind without using constrains from borehole or log data. However when compared both data we found that the S-wave velocity given by ReMi profiles like the abergae of the S-wave data given by both crosshole or downhole data each time.

Eight different sites with different soils were investigated to show the validity of ReMi Microtremors test In Egypt, Damietta, Sidi Krir, Mahmoudia, Nubaria, EL Tebbin, Alexanderia, Mokattam and Beni Suef. Almost all soil types are sedimentary soil, varying between very weak soil (soft clay at Damietta) into hard rock (Limestone at Mokattam). At least 400 seconds microtremors records were taken at each site using 48 channels or 12 channels Geometrics seismograph. Normal $14 \mathrm{~Hz}$, geophones were used in all tests. Almost all sites were found very noisy from big machines such as electrical turbines (power stations), construction activities (Loader and hammers) or big winches for loading and unloading (Damietta harbor).

Although some scientists are dealing with the longer period microtremors originated from farther distances (oceanographic disturbances) excluding urban excited sites where high degree of local cultural noise exist [19], we found that all previous kinds of noise are capable to estimate good S-wave velocity models if compared with other data (downhole and crosshole tests).

Our investigations have shown that the ReMi surface-wave method is an excellent technique for determining the shear wave velocities. It compared very well with crosshole and downhole results obtained from different soil types in Egypt. 20 seconds X 20 records (total 400 seconds) acquired using the 48 channel seismograph gave high resolution P-f images and dispersion curves, however 8 seconds X 50 records (total 400 seconds) using 12-channel records or 0.5 seconds $X 200$ records (Total 100 seconds) reflection records also provided good results - showing the robustness of the method. At calm sites, P-f images were not good enough to estimate good dispersion curves. In such a case it was better to increase the amount of noise by driving a vehicle and walking along the array or using hammer at the beginning and end of the profile to generate surface waves. Noisy sites provided the best data and these are the sites were crosshole and downhole fail to give good signals. It is better to collect ReMi data in these conditions. The present study proved that the ReMi test is a very suitable test to be used in Egypt for different soils to estimate the average shear wave velocity. Especially in very noisy sites were crosshole sources will fail to overcome the noise signals which is more powerful than the crosshole source itself.

\section{Acknowledgements}

Sincere thanks to the all Electrical power stations staff 
who permitted the work kindly. Also Optim, who provided support and software.

\section{References}

[1] J. N. Louie, "Faster, Better: Shear-Wave Velocity to 100 Meters Depth from Refraction Microtremors Arrays," Bulletin of the Seismological Society of America, Vol. 91, No. 2, 2001, pp. 347-364. doi:10.1785/0120000098

[2] S. Pullammanappallil, B. Honjas, J. Louie, J. A. Siemens and H. Miura, "Comparative Study of the Refraction Microtremors Method: Using Seismic Noise and Standard P-Wave Refraction Equipment for Deriving 1D ShearWave Profiles," Proceedings of the 6th SEGJ International Symposium, Tokyo, January 2003, pp. 192-197.

[3] R. Said, "The Geology of Egypt," Conco Hurghada Inc., Rotterdam, 1990.

[4] EGSMA, Geological Map of Greater Cairo Area. Outline of Geology Stratigraphy, Egyptian Geological Survey and Mining Authority, 1983.

[5] J. R. Thorsonand J. F. Claerbout, "Velocity-Stack and Slant-Stack Stochastic Inversion," Geophysics, Vol. 50, No. 12, 1985, pp. 2727-2741. doi:10.1190/1.1441893

[6] M. Horike, "Inversion of Phase Velocity of Long-Period Microtremors to the S-Wave-Velocity Structure Down to the Basement in Urbanized Areas," Journal of Physics of the Earth, Vol. 33, 1985, pp. 59-96. doi:10.4294/jpe1952.33.59

[7] R. W. Clayton and G. A. McMechan, "Inversion of Refraction Data by Wavefield Continuation," Geophysics, Vol. 46, No. 3, 1981, pp. 860-868. doi:10.1190/1.1441224

[8] G. Fuis, W. Mooney, J. Healy, G. McMechan and W. Lutter, "A Seismic Refraction Survey of the Imperial Valley Region, California," Journal of Geophysical Research, Vol. 89, No. B2, 1984, pp. 1165-1190. doi:10.1029/JB089iB02p01165

[9] G. A. McMechan and M. J. Yedlin, "Analysis of Dispersive Waves by Wave Field Transformation,” Geophysics, Vol. 46, No. 6, 1981, pp. 869-874.

doi:10.1190/1.1441225
[10] C. B. Park, R. D. Miller and J. Xia, "Imaging Dispersion Curves of Surface Waves on Multi-Channel Record," Annual Meeting Abstracts, Society of Exploration Geophysicists, Tulsa, 1998, pp. 1377-1380.

[11] R. D. Miller, C. B. Park, J. M. Ivanov, J. Xia, D. R. Laflen, and C. Gratton, "MASW to Investigate Anomalous Near-Surface Materials at the Indian Refinery in Lawrenceville,” Kansas Geology Survey, Open-File Report, Lawrence,2000, p. 48.

[12] S. Nazarian and K. H. Stokoe II, "In Situ Shear Wave Velocities from Spectral Analysis of Surface Waves," Proceedings of the World Conference on Earthquake Engineering, Vol. 8, San Francisco, 21-28 July 1984.

[13] C. B. Park, R. D. Miller and J. Xia, "Multi-Channel Analysis of Surface Waves," Geophysics, Vol. 64, No. 3, 1999, pp. 800-808. doi:10.1190/1.1444590

[14] M. Saito, "Computations of Reflectivity and Surface Wave dispersion Curves for Layered Media; I, Sound Wave and SH Wave,” Butsuri-Tanko, Vol. 32, No. 5, 1979, pp. 15-26.

[15] M. Saito, "Compound Matrix Method for the Calculation of Spheroidal Oscillation of the Earth," Seismological Research Letters, Vol. 59, 1988, p. 29.

[16] Y. Zeng and J. G. Anderson, "A Method for Direct Computation of the Differential Seismograms with Respect to the Velocity Change in a Layered Elastic Solid,” Bulletin of the Seismological Society of America, Vol. 85, No. 1, 1995, pp. 300-307.

[17] T. Iwata, H. Kawase, T. Satoh, Y. Kakehi, K. Irikura, J. N. Louie, R. E. Abbott and J. G. Anderson, "Array Microtremor Measurements at Reno, Nevada, USA,” EOS, Transactions of the American Geophysical Union, Vol. 79, No. 45, p. F578.

[18] J. Xia, R. D. Miller and C. B. Park, "Estimation of Near-Surface Shear-Wave Velocity by Inversion of Rayleigh Wave," Geophysics, Vol. 64, No. 3, 1999, pp. 691700. doi:10.1190/1.1444578

[19] E. H. Field, S. E. Hough and H. Jacob, "Using Microtremors to Assess Potential Arthquake Site Response, a Case Study in Flushing Meadows, New York City," Bulletin of the Seismological Society of America, Vol. 80, No. 6A, 1990, pp. 1456-1480. 